Tohoku J. Exp. Med., 1989, 159, 139-145

\title{
Increased Hexokinase Activity in Fetuses of Rats Developed under Maternal Hyperglycemia
}

\author{
Yutaka Wako, Kenichi Suzuki, ${ }^{*}$ Aкiniko Isobe $\dagger$ and \\ Shuichi Kimura \\ Laboratory of Nutrition, Faculty of Agriculture, Tohoku \\ University, Sendai 980, *the Third Department of Internal \\ Medicine, Tohoku University School of Medicine, Sendai \\ 980, and †Laboratory of Chemistry, Gunma Prefectural \\ Women's College, Gunma 370-11
}

Wako, Y., Suzuki, K., Isobe, A. and Kimura, S. Increased Hexokinase Activity in Fetuses of Rats Developed under Maternal Hyperglycemia. Tohoku J. Exp. Med., 1989, $159(2), 139-145-$ Hepatic and diaphragmatic hexokinase (HK) activities increased in fetuses of rats developed under maternal hyperglycemic conditions, compared to those in normal controls. In those organs, Type I and Type II hexokinase isozymes were detected by electrophoresis and densitometry with a chromatoscanner. Densitometric peak that corresponded to hepatic and diaphragmatic Type II hexokinase was also increased in the fetuses developed under hyperglycemia, compared to that of normal fetuses. These findings suggest that in the fetal liver, where significant activity of Type IV was absent, activity of Type II hexokinase varied depending on physiological state such as maternal hyperglycemia. —_ fetus; hexokinase; hexokinase isozyme pattern; hyperglycemia

Little study has been reported in respect to the mechanisms of glucose metabolism in the fetus. Beatty et al. (1976) have studied intermediates and cofactors of the glycolytic pathway using fetal skeletal muscle of Rhesus monkeys and calculated mass action ratios for each of the reactions. They suggested that reactions catalysed by hexokinase, phosphofructokinase (PFK) and pyruvate kinase are also nonequilibrium and possibly rate-limiting for glycolysis in the fetal muscle as seen in the adult tissue. Glucose metabolism in the fetus is likely to be controlled as same manner as that in the adult in principle. On the contrary, some studies evaluated differences in anaerobic glycolytic rate or glycolytic enzyme activity between adults and fetuses (Villee et al. 1958; Burch et al. 1963). Therefore it is generally considered that in the overall regulation of

Received August 2, 1989; revision accepted for publication September 30, 1989.

Present address : Yutaka Wako, Laboratory of Food Technology, Hachinohe Institute of Technology, Hachinohe 031, Japan. 
the glucose metabolism there is no major difference between fetuses and adults but some ways of regulation are characteristic in fetuses.

Previously, to elucidate the metabolic control of glucose utilization in the fetus, we compared the diaphragmatic glucose uptake between fetuses of diabetic pregnant rats and normal fetuses (Wako and Kimura 1984). The fetuses of diabetic pregnant rats were loaded with hyperglycemia since maternal glucose in the circulation crosses the plancenta freely. Metabolic adaptation observed in these fetuses in response to maternal hyperglycemia. In the present study we investigated diaphragmatic and hepatic hexokinase activity and the isozyme pattern in the fetus of normal and diabetic pregnant rats.

\section{Materials and Methods}

Animals. Four virginal female Wistar rats weighing $230-280 \mathrm{~g}$ were used. Two of them were injected intraperitoneally with streptozotocin $(45 \mathrm{mg} / \mathrm{kg}$ of body weight; Sigma Chemical Co., St. Louis, MO, USA) dissolved in citrate buffer (0.01 M, pH 4.0). After having confirmed the elevation of plasma glucose level in the injected rats, normal and diabetic virgin rats were mated and thereafter varginal plug and sperms were checked to confirm the day 0 of pregnancy. The pregnant rats at the 22nd day of gestation were sacrificed by decapitation and the fetuses were taken by Caesarean operation. The maternal weight change, plasma glucose level and litter size are shown in Table 1 .

Measurement of glucose in plasma. The rats were killed by decapitation and blood samples were collected in heparinized test tubes, and centrifuged immediately. Plasma glucose was measured by a glucose-oxidase method (Glucose C-Test, Wako Pure Chemical Industries, Osaka).

Measurement of hexokinase activity. Hexokinase activity was assayed by a modified method based on those of Sharma et al. (1963) and Shonk and Boxer (1964). The diaphragm and liver were homogenized in an equal volume of $0.1 \mathrm{M}$ Tris-HCl buffer $(\mathrm{pH} 7.4)$ by using a coaxial homogenizer fitted with a teflon pestle. The homogenate was centrifuged at $105,000 \times g$ for $30 \mathrm{~min}$ and the supernatant cytosol fraction was assayed for hexokinase activity. The reaction mixture contained Tris- $\mathrm{HCl}$ buffer $(50 \mathrm{mM}), \mathrm{pH} 7.6, \mathrm{MgCl}_{2}(5 \mathrm{mM})$, ATP $(5 \mathrm{mM})$, glucose $(0.5 \mathrm{mM})$, NADP $(0.5 \mathrm{mM})$, and 0.2 units of glucose 6-phosphate dehydrogenase (G6PD). The reaction was started by the addition of cytosol fraction. The $\mathrm{NADPH}_{2}$ formation was measured spectrometrically at $340 \mathrm{~nm}$ at $15 \mathrm{~min}$ and $30^{\circ} \mathrm{C}$. Determination of protein was by the method of Lowry et al. (1951).

Column chromatography. The DEAE-Sephadex A-50 column chromatographic analy-

TABLE 1. Maternal body weight gains and plasma glucose in normal and diabetic pregnant rats

\begin{tabular}{lcccccc}
\hline \multicolumn{1}{c}{ Groups } & & \multicolumn{2}{c}{ Normal } & & \multicolumn{2}{c}{ Diabetic } \\
\cline { 6 - 7 } \cline { 5 - 6 } $\begin{array}{c}\text { Identification number } \\
\text { of animal }\end{array}$ & & 1 & 2 & & 3 & 4 \\
\hline Initial body wt. $(\mathrm{g})$ & 240 & 235 & & 272 & 245 \\
Body wt. at day $22^{*}(\mathrm{~g})$ & & 400 & 375 & & 418 & 375 \\
Plasma glucose $\dagger(\mathrm{mg} / 100 \mathrm{ml})$ & & 149.0 & 152.8 & & 320.3 & 408.5 \\
Litter size & 16 & 12 & & 12 & 13 \\
\hline
\end{tabular}

*22nd day of gestation. t0 day of gestation. 
sis of enzyme extracts was carried out according to the method described by Katzen and Schimke (1965). Rat livers were homogenized in an equal volume of $10 \mathrm{mM}$ potassium phosphate buffer containing $5 \mathrm{mM}$ EDTA and $5 \mathrm{mM}$ mercaptoethanol, final $\mathrm{pH} 7.0$, and centrifuged for $60 \mathrm{~min}$ at $104,000 \times \mathrm{g}$. The resultant extract was dialyzed against the above buffer solution. The extract was applied to a DEAE-Sephadex column $(1.2 \times 20 \mathrm{~cm})$ equilibrated with the above phosphate buffer. Following an initial washing of the column with equilibrating solution, the column was developed with $100 \mathrm{ml}$ of $0-0.6 \mathrm{M}$ linear gradient of $\mathrm{KCl}$ in the phosphate buffer. Fractions ( $1 \mathrm{ml}$ each) were collected. Hexokinase activity of the eluted fractions was measured as mentioned above, but glucose concentration was $35 \mathrm{mM}$ instead of $0.5 \mathrm{mM}$.

Electrophoresis. Cellulose acetate electrophoresis was done by the method described by Sato et al. (1969). Four $\mu l$ of the enzyme extract was placed on a cellulose acetate membrane (Karltzise, $\mathrm{FRG}$ ), and electrophoresis was run at $4^{\circ} \mathrm{C}$, in veronarl buffer $(\mathrm{pH} 8.6$, $\mathrm{I}=0.05$ ) supplemented with $5 \mathrm{mM}$ EDTA, $1 \mathrm{mM}$ 2-mercaptoethanol, and $10 \mathrm{mM}$ glucose for $2 \mathrm{hr}$ at $0.8 \mathrm{~mA} / \mathrm{cm}$. Then the bands of hexokinase isozymes were stained by placing the membrane on $1 \%$ agar gel plate containing $0.5 \mathrm{mM}$ glucose, $5 \mathrm{mM} \mathrm{ATP}, 5 \mathrm{mM} \mathrm{MgCl}_{2}$, $0.4 \mathrm{unit} / \mathrm{ml}$ of G6PD, $1 \mathrm{mM}$ NADP, $2 \mathrm{mM} \mathrm{KCN}, 25 \mu \mathrm{g} / \mathrm{ml}$ phenazine methosulfate, $0.4 \mathrm{mg} /$ $\mathrm{ml}$ nitroblue tetrazolium, and $0.1 \mathrm{M}$ Tris- $\mathrm{HCl}$ buffer $(\mathrm{pH} 7.4)$, for 40 min at $37^{\circ} \mathrm{C}$ in the dark. Densitometry of hexokinase isozyme bands on the membrane was performed with Shimadzu Chromato scanner, Model CS-900 of photovolt with a $525 \mathrm{~nm}$ filter. As blank, glucose and ATP were omitted from the agar gel plate for staining.

\section{Results and Discussion}

Hexokinases constitute a family of four enzymes at Type I, II, III and IV (Katzen and Schimke 1965). Types I, II and III considered as the low $\mathrm{Km}$ hexokinases are distributed widely in various kinds of tissues, while the presence of Type IV (glucokinase) with very high $\mathrm{Km}$ value is limited in the liver, adipose tissue and brain. As hepatic Type IV hexokinase develops at the postnatal period, its activity is undetectable in the fetus liver (Walker and Holland 1965). The DEAE-Sephadex column chromatographic patterns of the hepatic hexo-

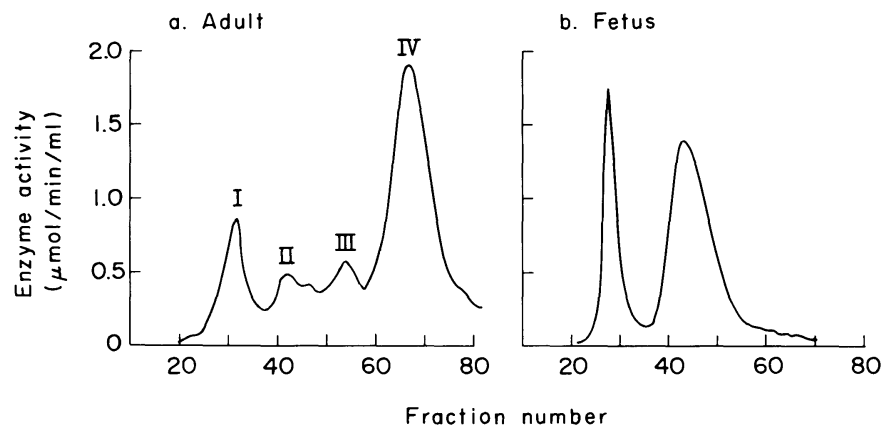

Fig. 1. DEAE-Sephadex column chromatography of hexokinases from the adult and fetus rat liver. Enzyme extract was adsorbed on a column $(1.2 \times 20 \mathrm{~cm})$ equilibrated with $10 \mathrm{mM}$ phosphate buffer, $\mathrm{pH}$ 7.0. Enzyme was eluted with $100 \mathrm{ml}$ of linear gradient $\mathrm{KCl} 0-0.6 \mathrm{M}$ in the phosphate buffer. Fractions (1 $\mathrm{ml}$ each) were assayed for hexokinases with concentration of $35 \mathrm{mM}$ glucose. Enzyme activity was expressed as $\mu$ moles of product formed per minute per $\mathrm{ml}$ of effluent at $30^{\circ} \mathrm{C}$. 
kinases in the fetal and adult rats in the present study were showed in Fig. 1. The hexokinase activities of the adult liver were on the 4 peaks (Fig. 1a). These peaks were Type I, II, III and IV hexokinases in order of elution with an increasing concentration of $\mathrm{KCl}$ according to Katzen and Schimke (1965). Fig. $1 \mathrm{~b}$ shows the elution profiles of hexokinase in the fetal liver. The first and second eluted peaks corresponded to Type I and Type II, respectively, in Fig. 1a. This result suggests that in the fetal liver, glucose phosphorylation was catalized by the Type I and II of hexokinases predominantly.

We investigated how the response of the activities and isozyme patterns of hexokinases depend on nutritional factors in the diaphragm and liver at the late stage of the rat fetus. Mamalian embryo takes its nutrient from its mother across the placenta. Maternal glucose crosses the placenta freely by facilitated diffusion. Consequently, the fetus was loaded high glucose concentration during induction of maternal diabetes. Table 1 shows values of the body weight, plasma glucose level and litter size in the pregnant rats in this study. The plasma glucose level increased in the diabetic pregnant rats compared to their normal control groups. The fetuses of diabetic pregnant rats had higher plasma glucose levels compared to normal fetuses $(383.5 \pm 33.6 \mathrm{mg} / 100 \mathrm{ml}$ vs. $93.7 \pm 12.1 \mathrm{mg} / 100 \mathrm{ml}$; $n=10$ in both group). There was no difference in body weight between the fetuses of diabetic and normal pregnant rats $(5.29 \pm 0.41 \mathrm{~g}$ vs. $5.12 \pm 0.26 \mathrm{~g} ; n=25$ and 28 in each group). The activitis of hepatic and diaphragmatic hexokinases are shown in Table 2 . The significantly elevated levels of hexokinases were detected in the liver and diaphragm of the fetuses developed under hyperglycemia as compared with the normal controls. Large babies were often born from the diabetic mother. This excessive body weight is due to increased deposition of fat and glycogen resulting from increased glucose utilization (Pedersen 1977). Previously, we also reported that the incroporation of radiolabeled glucose into diaphragmatic glycogen was greater in the fetuses of diabetic mothers than in normal fetuses (Wako and Kimura 1984). Thus, it is implied that hexokinase activities are elevated and cause enhancement of glucose anabolism in the fetuses developed under hyperglycemia.

TABLE 2. Hexokinase activity in the 22nd day fetuses of rats developed under normal and hyperglycemic pregnancy

\begin{tabular}{lcc}
\hline \multicolumn{1}{c}{ Groups } & \multicolumn{1}{c}{ Normal } & Hyperglycemia \\
\hline & \multicolumn{2}{c}{$(\mathrm{nmol} / \mathrm{min} /$ tissue } \\
& $392.8 \pm 29.6(10)$ & $528.8 \pm 49.7^{* *}(10)$ \\
Liver (/liver) & $28.62 \pm 1.63(10)$ & $37.52 \pm 3.81^{* *}(10)$ \\
Liver (/mg protein) & $16.84 \pm 1.75(5)$ & $24.16 \pm 4.43^{* *}(5)$ \\
Diaphragm (/mg protein) &
\end{tabular}

Values are means \pm S.D. The number of observation is in parentheses. ${ }^{* *} p<$ 0.01 against values in the normal group. 


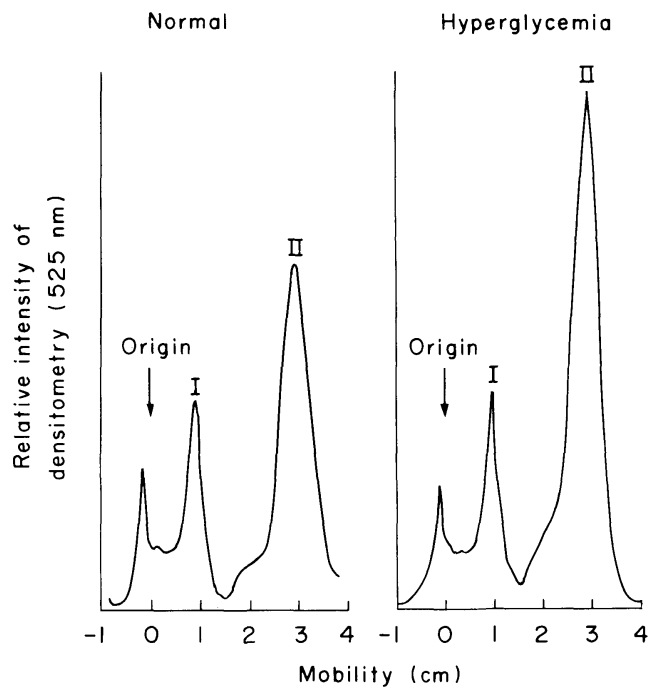

Fig. 2. Densitometric tracings of hepatic hexokinase isozyme bands on cellulose acetate membranes of the fetus from normal and hyperglycemic mothers. Electrophoresis was carried out at $0^{\circ} \mathrm{C}$ in veronal buffer $(\mathrm{pH} 8.6, \mathrm{I}=0.05)$ for $2 \mathrm{hr}$ at $0.8 \mathrm{~mA} / \mathrm{cm}$. Hexokinase isozyme bands were stained on an agar gel plate in $0.5 \mathrm{mM}$ glucose.

Fig. 2 shows typical densitometric tracings of the hepatic hexokinase isozyme bands of the fetus developed under normal and hyperglycemia. Three distinct bands were separated on the cellulose acetate membrane. Whereas, the first band migrating for cathodic side was also stained in the staining gel without glucose and ATP indicating that this band did not correspond to an isozyme of hexokinases (Kaplan and Beutler 1968). The mobility of the second or third band was compared with that of the purified hexokinase isozyme types eluted from the DEAE-Sephadex column. The mobility of the second or third band was consisted with that of DEAE fractions containing Type I or Type II of hexokinase, respectively (data are not shown). Therefore 2 band were regarded as Type I and Type II hexokinase, respectively. Proportion of these hexokinase activities was compared between in the fetuses developed under hyperglycemia and in the normal fetuses. The areas of densitometric tracing bands were measured. The relative percentage of peak areas were determined on the assumption that the average of Type I peak area in normal fetus group was regarded as $100 \%$ (Table 3 ). The proportion of the hepatic Type II peak area was elevated in the fetuses developed under hyperglycemia. The percentages of diaphragmatic Type I and Type II peak areas were both increased in the fetus of diabetic pregnant rats. While magnitude of increase in the Type II peak was greater than those in the Type I peak (1.23 times vs. 1.44 times; compared to normal group). These data suggest that the elevation of the hepatic and diaphragmatic hexokinase activity consisted largely of increase in Type II activity. 
TABLE 3. Relative percentage of densitometric peak areas corresponding to hexokinase isozyme bands in the fetuses of rats developed under normal and hyperglycemic pregnancy

\begin{tabular}{lccccc}
\hline \multicolumn{1}{c}{ Groups } & \multicolumn{3}{c}{ Normal } & & \multicolumn{3}{c}{ Hyperglycemia } \\
\cline { 1 - 3 } \cline { 5 - 6 } HK Types & I & II & \multicolumn{2}{c}{ I } & II \\
\hline & & & $(\%)$ & & \\
Liver & 100 & 189 & 92 & 293 \\
Diaphragm & 100 & 299 & & 123 & 430 \\
\hline
\end{tabular}

Values are averages of four determinations. Relative percentages of peak areas were determined on the assumption that the average of Type I peak area in normal group was regarded as $100 \%$. HK, hexokinase.

Changes could be predicted in hepatic hexokinase activity as a function of physiological state of the animal. In the adult rat liver, the activity of Type IV hexokinase varies depending on starvation, diabetes or insulin treatment, but the activities of low Km hexokinases changed only slightly (Salas et al. 1963 ; Sharma et al. 1963). While, the present study showed that in the fetal liver, where the significant activity of Type IV could not be detected, the activity of Type II changed under maternal hyperglycemia. Therefore in the fetal liver adaptive changes seemed to occur in Type II isozyme instead of Type IV. Already, in the adipose tissue or muscle, variability of Type II hexokinase in response to various physiological state was pointed out (Katzen and Schimke 1965; Moore et al. 1964). The activity of Type II hexokinase in the adipose tissue significantly decreased in the diabetic rat (McLean et al. 1966). Hormonal regulation of Type II hexokinase was further indicated ; in vitro incubation of fat pad from diabetic animal with insulin resulted in restoration of the activity of Type II hexokinase (Borrebaek 1967). In addition, fat pad, muscle and heart, which contain a large amount of Type II hexokinase, are highly insulin sensitive. Consequently insulin appears to be a necessary factor for the level of Type II hexokinase increase. Previously we indicated that the increase of serum insulin concentration in the fetus of diabetic mothers (Wako and Kimura 1984). Thus it may be considered that hyperinsulism contributed to the elevation of hepatic and diaphragmatic Type II hexokinase in the fetus developed under hyperglycemia.

Physiological roles of hexokinase isozymes in glucose metabolism were discussed based on differences in their $\mathrm{Km}$ values for glucose. Because of high $\mathrm{Km}$ value for glucose $\left(2 \times 10^{-2} \mathrm{M}\right)$, Type IV hexokinase controls glucose uptake to keep the overall homeostasis of glucose metabolism in face of dynamic metabolic changes such as feeding or starvation. On the other hand, Type I and III hexokinases with low $\mathrm{Km}$ values $\left(10^{-5} \mathrm{M}, 10^{-6} \mathrm{M}\right.$ respectively) may regulate the constant intracellular glucose metabolism. Type II has relatively high $\mathrm{Km}$ value $\left(10^{-4} \mathrm{M}\right)$ compared to those of Type I and III, and is inducible depending on 
various physiological changes. In view of these nature, Type II hexokinase is regarded as a regulative enzyme in the systemic control of glucose metabolism.

The present study shows that in the fetus developed under hyperglycemia the activities of hepatic and diaphragmatic hexokinases increase. This increase is probably owing to the elevation of Type II isozyme activity predominantly. This may imply a characteristic of regulation of glycolysis in the fetal liver.

\section{References}

1) Beatty, C.H., Young, M.K. \& Bocek, R.M. (1976) Control of glycolysis in skeletal muscle from fetal Resus monkys. Pediatr. Res., 10, 149-153.

2) Borrebaek, B. (1967) Adaptable hexokinase activity in epididymal adipose tissue studied in vivo and in vitro. Biochim. Biophys. Acta, 141, 221-230.

3) Burch, H.B., Lowry, O.H., Kuhlman, A.M., Skerjance, J., Diamant, E. J., Lowry, S.R. \& von Dippe, P. (1963) Changes in patterns of enzymes of carbohydrate metabolism in the developping rat liver. J. Biol. Chem., 238, 2267-2273.

4) Kaplan, J.C. \& Beutler, E. (1968) Hexokinase in human erythrocytes. Science, 159, 215-216.

5) Katzen, H.M. \& Schimke, R.T. (1965) Multiple forms of hexokinase in the rat: Tissue distribution, age dependency, and properties. Proc. Natl. Acad. Sci. USA, 54, $1218-1225$.

6) Lowry, O.H., Rosenbrough, N.J., Farr, A.L. \& Randall, R.J. (1951) Protein measurement with the folin phenol reagent. J. Biol. Chem., 193, 265-275.

7) McLean, R.J., Brown, J., Greeslade, K. \& Brew, K. (1966) Effect of alloxan-diabetes on the glucose-ATP phosphotransferase activity of adipose tissue. Biochem. Biophys. Res. Commun., 23, 117-121.

8) Moore, R.O., Chandler, A.M. \& Tettenhorst, N. (1964) Glucose-ATP transferases in adipose tissue of fasted and refed rats. Biochem. Biophys. Res. Commun., 17, 527531.

9) Pedersen, J. (1977) Problems and manegement. In: The Pregnant Diabetic and Her New Born, 2nd ed., Williams \& Wilkins, Baltimore, pp. 211-220.

10) Salas, M., Viñuela, E. \& Sols, A. (1963) Insulin-dependent synthesis of liver glucokinase in the rat. J. Biol. Chem., 238, 3535-3541.

11) Sato, S., Matsushima, T. \& Sugimura, T. (1969) Hexokinase isozyme patterns of experimental hepatomas of rats. Cancer Res., 29, 1473-1446.

12) Sharma, C., Manjeshwar, R. \& Weinhouse, S. (1963) Effects of diet and insulin on glucose-adenosine triphosphate phosphotransferase of rat liver. J. Biol. Chem., 238, $3840-3845$.

13) Shonk, C.E. \& Boxer, G.E. (1964) Enzyme patterns in human tissues. I. Methods for the determination of glycolytic enzymes. Cancer Res., 24, 709-721.

14) Villee, C.A. Hagerman, D.D., Holmberg, N., Lind, J. \& Villee, D.B. (1958) The effect of anoxia on the metabolism of human fetal tissues. Pediatrics, 22, 953-971.

15) Wako, Y. \& Kimura, S. (1984) Muscle response to insulin in fetuses of diabetic pregnant rats. Agric. Biol. Chem., 48, 2669-2674.

16) Walker, D.G. \& Holland, G. (1965) The development of hepatic glucokinase in the neonatal rat. Biochem. J., 97, 845-854. 